\title{
The effect of spring burning on competitive ranking of prairie species
}

\author{
Suding, Katharine Nash \\ Department of Ecology and Evolutionary Biology, University of Michigan, Ann Arbor, MI 48109, USA; \\ Current address: Institute of Alpine and Arctic Research, and Department of Environmental, Population, \\ and Organismal Biology, University of Colorado, Boulder, CO 80309-0450, USA; \\ Fax +13034928699; E-mail katharine.suding@colorado.edu
}

\begin{abstract}
A common explanation for the changes in species abundance following a fire is a shift in competitive ranking. However, experimental tests have been inconsistent and generally do not support this explanation. I examined the competitive ability of an abundant $\mathrm{C}_{4}$ grass, Andropogon gerardii, and $\mathrm{a}_{3}$ forb, Ratibida pinnata, in a prairie remnant in northern Ohio, USA, for each of three years following a spring burn in 1996. While the abiotic environment directly influenced both species similarly, relative competitive abilities in terms of growth changed markedly: in 1996 Andropogon was less inhibited by neighbors; in 1997 both Andropogon and Ratibida had similar competitive abilities; and in 1998 Ratibida was less inhibited by neighbors. This shift in competitive response ranking paralleled the changes in relative abundance for the two species. In contrast, the effect of neighbors on survival changed markedly over time but did not differ among the two species. Thus, fire may influence species abundance through changing species competitive response ranking, at least in terms of growth.
\end{abstract}

Keywords: Andropogon gerardi; Climate variation; Fire; Ratibida pinnata; Species abundance;Tall-grass prairie plant community.

Nomenclature: Voss $(1972,1985,1996)$.

Abbreviations: $\mathrm{RGR}=$ Relative growth rate; $\mathrm{RR}=$ Response ratio.

\section{Introduction}

Periodic fire is essential for the development and maintenance of many plant communities (e.g. Collins \& Wallace 1990; Belsky 1992; Noy-Meir 1995; Morgan 1998). Species abundance often changes following fire (Gibson \& Hulbert 1987; Turner et al. 1995; Morgan 1998), and a common explanation for the changes is that competitive interactions shift (Belsky 1992; Gurevitch \& Collins 1994; Whelen 1995; Vilà \& Sardans 1999). Two types of evidence indirectly support this explanation. First, changes in physiology and growth often parallel changes in species relative abundance (e.g. Moreno \& Oechel 1992; Turner et al. 1995; Turner \& Knapp 1996). Second, changes in total biomass, presumably related to overall competitive intensity, are associated with changes in species relative abundance following burning (e.g., Old 1969; Gibson \& Hulbert 1987; Abrams 1988; Lloret 1998).

Aside from indirect support, however, there are few direct experimental tests of changes in competitive interactions following fire, and among these, results are inconsistent. One study (Wilson \& Shay 1990) found that burning did not influence species relative competitive abilities or their relative abundances, consistent with the competition hypothesis. However, contrary to expectations, several studies found that burning did not change relative competitive abilities, although it did change species relative abundance (Vilà \& Terradas 1995; Brewer 1999; Quintana-Ascencio \& Menges 2000; Vilà \& Lloret 2000). Also contrary to expectations, Inchausti (1995) found a shift in relative competitive rankings, but this did not correspond to the change in relative abundances. Taken together, this work lends little support to the general hypothesis that changes in species relative abundances following burning reflect changes in competitive interactions.

At least three other factors could explain the changes in species abundances following fire. First, fire has been found to enhance plant productivity (Ojima et al. 1994; Briggs \& Knapp 1995), increase microbial activity (Ojima et al. 1994) and release nutrients (Marion et al. 1991; Turner et al. 1997). Plants that are more abundant soon after a fire may be more successful under these changed conditions, irrespective of the influence of competitive interactions. Alternatively, change in species abundance following fire could reflect differences in species maximal growth rates: slower-growing species could simply take a longer time to accumulate biomass, increasing in relative abundance over time. Thirdly, post-fire reduction in herbivores or pathogens may allow susceptible species to escape enemies, and as enemies recolonize the burned areas, more tolerant plant 
species may become more abundant (Moreno \& Oechel 1991; Tyler 1996; Ford \& Grace 1998).

In this paper the assumption is tested that changes in competitive ability are responsible for changes in abundance of two prairie plant species following fire. The competitive response ability is assessed of juveniles of two tall-grass prairie species, a $\mathrm{C}_{4}$ grass, Andropogon gerardii and $\mathrm{a}_{3}$ forb, Ratibida pinnata, in each of three years following a spring burn in 1996. In North American tall-grass prairies, $\mathrm{C}_{4}$ grasses, such as Andropogon, tend to increase in relative abundance immediately following a fire and then decline as forb species, like Ratibida, become relatively more abundant (Turner et al. 1995; Gibson \& Hulbert 1987). If changes in competitive response ability are responsible for changes in abundance, then (1) in a recently burned prairie, Andropogon should become less inhibited by neighbors than Ratibida and (2) as the community recovers from the burning, Ratibida should become less suppressed by competition compared to Andropogon.

Predictions were tested using temporal comparisons over three years following a fire. It is often difficult to randomize burned and unburned areas without utilizing unnaturally small burns where fire may not influence ecosystem dynamics as it would over a larger spatial scale (Glenn-Lewin et al. 1990; Collins 1992). Instead, I examined how interactions vary as a function of time at one location, initiating separate experiments immediately, one year, and two years following a spring burn. Because this approach cannot separate the influence of time since disturbance from climatic variation, I also examined the effect of climate variability on species response. In addition, I test the alternative hypotheses that direct environmental effects and differences in maximal growth are associated with the changes in relative abundance of Andropogon and Ratibida following fire.

\section{Material and Methods}

This study was performed in a grassland at the Resthaven Wildlife Area (Ohio Department of Natural Resources) near Castalia, Ohio, USA. The site is a 100acre remnant of the prairie peninsula, part of the easternmost extension of tall-grass prairie in North America. The area was acquired by the state of Ohio in 1942 and has been managed by burning every 2 - 3 yr since 1972 .

\section{Climate information}

Climate data (Midwestern Climate Center, Champaign, IL) from the weather station closest to the site (Sandusky, OH, ca. $20 \mathrm{~km}$ northeast from the prairie) were used to determine how the climate differed among the three experimental years and from the historical average (1961 to 1990). Average daily temperature for each month and total monthly precipitation were analyzed using one-way ANOVA models with year as a fixed factor. Days between precipitation events (drought length) was calculated throughout each growing season.

\section{Abundance and production patterns}

To determine whether above-ground biomass production followed patterns typically found after burning, in each year five to eight plots, $50 \mathrm{~cm}$ in diameter, were selected at random, each adjacent to one block of the competition experiment (see below). At peak biomass, all above-ground biomass originating within the plot was clipped and separated into live vegetation and dead litter. Further the 'dominant' grasses (Andropogon gerardii and Sorghastrum nutans) were sorted from the rest of the vegetation. The biomass was dried to constant mass and weighed. In 1996 and 1998 cover of all species was visually estimated in $0.5 \mathrm{~m}$ diameter unmanipulated plots throughout the study site. A one-way ANOVA model with year as a fixed factor was used to analyse vegetation mass and species relative abundance. A Kruskal-Wallis model was used for litter mass because it did not satisfy the assumptions of equal variances.

\section{Potential performance and competitive response}

To assess the direct effect of the environment and competitive response ability for each species following burning, I conducted three separate experiments each lasting a single growing season. On 26 April 1996, the prairie was burned. The first experiment was established 28 May 1996 and harvested 5 October 1996. A second experiment, established 30 May 1997 and harvested 27 September 1997, and a third experiment, established 1 June 1998 and harvested 20 September 1998 , followed similar protocols. In each year, the experiment had five (in 1996) or eight (in 1997 and 1998) replicate blocks. Each experiment (i.e. each year) had a separate block layout, although all blocks for all years were located in same area of the prairie and interspersed with no systematic spatial bias. Experimental plots were $0.5 \mathrm{~m}$ in diameter with, for the no neighbor treatments, an additional $0.3 \mathrm{~m}$ buffer zone of clipped vegetation around the edge. Plots were spaced at two-meter intervals.

Neighbors (both vegetation and litter) were either removed or left intact, and one of the target species was outplanted in each plot, for a total of four treatment combinations. Above- and below-ground vegetation was killed using the systemic herbicide Roundup (Monsanto, St. Louis, Missouri), and then the above-ground portion was removed by clipping. The minimal regrowth that 
occurred was weeded weekly. Individuals of Andropogon gerardii and Ratibida pinnata were grown from seed at the Matthaei Botanical Gardens (Ann Arbor, MI) for 18 to 22 days prior to transplanting. Seed was collected at the prairie each Fall. In the 1996 experiment, one individual was planted in the center of each experimental plot. In the 1997 and 1998 experiments, three targets were planted in the center of the plot, $12 \mathrm{~cm}$ apart. Analysis indicates multiple targets were spaced far enough apart to not affect each others' growth (Suding 1999). The initial number of leaves, basal diameter, and height of the planted targets and other representative seedlings were measured, and then the other seedlings were dried to constant mass and weighed. Regressions of above-ground biomass of these weighed seedlings on the non-destructive size measures were used to estimate the initial biomass of the planted targets.

Target individuals were harvested at the end of one growing season by clipping above-ground biomass. In a related study, Suding \& Goldberg (2001) found that root allocation of these species was not affected by competitive environment, indicating that above-ground response should be an appropriate measure of competition here. All harvested targets were dried to a constant mass and weighed.

To assess the direct effect of the environment on target response across the three years, two measures of absolute performance in the absence of neighbors were calculated: relative growth rate (RGR; growth/initial biomass/day) and (proportional) survival. Then, absolute measures with and without neighbors were compared to quantified relative measures of response competitive ability (Hedges et al. 1999). These natural-log transformed response ratios (ln RR) were calculated for each replicate block as follows:

Ln RR RGR= ln (RGR with neighbors present / RGR with neighbors removed)

Ln RR Survival $=$ ln (( Survival with neighbors present +1$)$

/ (Survival with neighbors removed +1$)$ )

Ln RR values are symmetrical around 0 , with positive values indicating facilitation and negative values indicating competition. Because the survival data contained zeros, one was added to both the numerator and denominator. Absolute growth rate values, as well as all response ratios, were natural log transformed to satisfy the assumptions of normality and homogeneity. I analyzed absolute growth and survival in the absence of neighbors, as well as competitive response ratios for growth and survival, in ANOVA models with target species (Andropogon and Ratibida) and experimental year (1996, 1997, and 1998) as fixed factors. Because blocks only contained treatments for a single year, a block factor was not included in the analysis. Values were tested for whether they differed from zero using Dunnett's one-sided test. This experiment measures the competitive response, but not the competitive effect, of these species. Competitive response is thought to indicate long-term persistence of populations in perennial, size-structured communities such as this grassland (Wilson \& Tilman 1995; Goldberg 1996).

\section{Results}

\section{Climate variation}

Average daily temperatures were similar among the experimental years except in the month of August (Fig. 1a). The average daily temperature in August was significantly lower in 1997 compared to 1996 or 1998 by more than two degrees. Rainfall also varied among the years; 1996 was about 35\% drier during the summer months in comparison to 1997 and 1998, which were almost identical in summer rainfall (Fig. 1b). This difference was almost entirely due to the lack of rainfall in August 1996, when the prairie received only $1 \mathrm{~cm}$ of precipitation during the entire month. Three extended drought periods, with no rainfall for over 10 days, occurred during the experiment (Fig. 1c). Two of these droughts, one 12 days long and one 16 days long, occurred in 1996. The other drought, lasting for 12 days, occurred in 1998.

\section{Biomass production}

Biomass production and litter mass accumulation significantly differed among experimental years (Fig. 2) and appear more related to burning than climate. Despite the much lower summer rainfall and two of the three longest droughts, vegetation mass was significantly greater in 1996 compared to 1998. This decline is typical following burning in North American tall-grass prairie. Also as expected, the relative biomass of the dominant grasses (Andropogon and Sorghastrum) followed a similar pattern, significantly declining from 1996 to 1998 (Fig. 2). Relative cover of Ratibida was $2.2 \pm 0.5 \%$ (mean $\pm \mathrm{SE}$ ) in 1996 and increased to $4.1 \pm$ $0.7 \%$ in 1998, while the relative cover of Andropogon was $29.5 \pm 3.2 \%$ in 1996 and decreased to $21.1 \pm 2.2 \%$ in 1998. Litter mass showed the opposite pattern, increasing from almost none in 1996 to more than the live vegetation mass in 1998.

\section{Performance in the absence of neighbors}

In contrast to the results for total vegetation mass in unmanipulated plots, the potential performance of isolated individuals in the absence of interactions was positively related to precipitation. Relative growth rate 

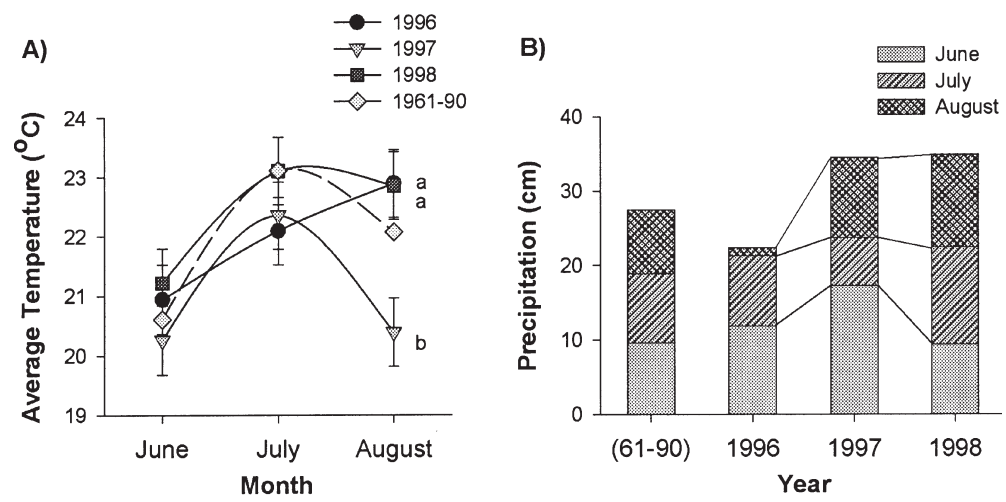

C)

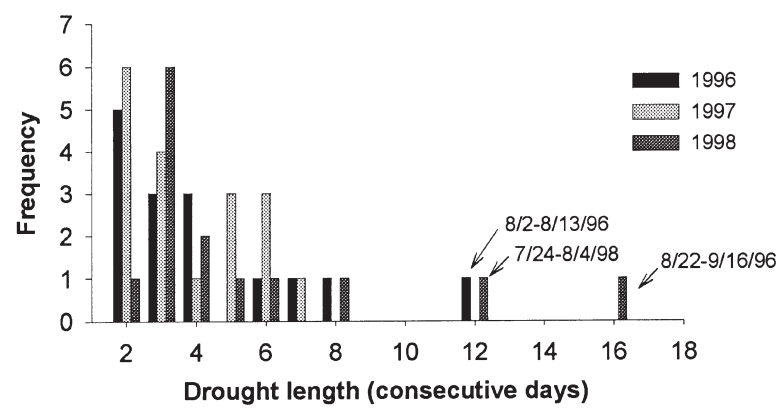

Fig. 1a. Average daily temperature (mean \pm 1 $\mathrm{SE})$ for each month of the growing season in 1996, 1997 and 1998, and the historical average (1961-1990). Different letters indicate significant differences among years for the month of $\mathrm{Au}-$ gust $(P<0.05$, Tukey multiple comparisons); the average daily temperature in June and July did not differ among years. b. Total precipitation, by month, for each year and the historical average (left bar; 1961-1990). c. The frequency of drought $(<0.1 \mathrm{~mm}$ rainfall) duration for the three experimental years. The three longest droughts are indicated. was slowest for both species in 1996 (Fig. 3a) when precipitation was much lower than 1997 and 1998. Species also differed from one another in growth: isolated individuals of Ratibida grew significantly faster (as much as $18 \times$ faster) than Andropogon in each year (Fig. 3a). Survivorship significantly differed among

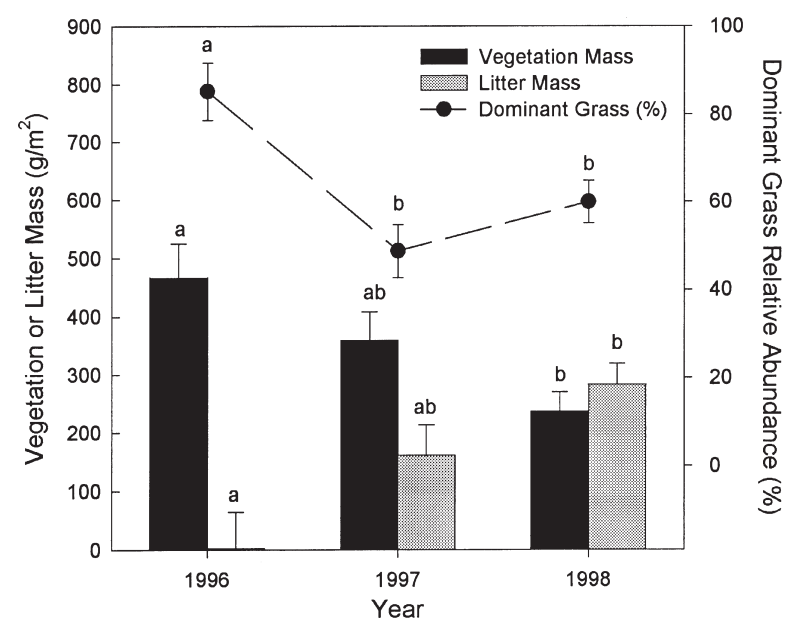

Fig. 2. Changes in vegetation and litter mass (left axis, mean \pm $1 \mathrm{SE}$ ) and the relative abundance of the $\mathrm{C}_{4}$ grasses (Andropogon and Sorghastrum)(right axis, mean \pm 1 S.E.). All three variables significantly differed among years $(P<0.05)$; different letters indicate significant differences $(P>0.05$, Tukey multiple comparisons). years, but not between species: survival was highest in 1997, the coolest summer, and lowest in 1998, the warmest summer (Fig. 3a). Thus, time since fire was not related to performance in the absence of interactions, inconsistent with the prediction that the direct effect of environmental changes may drive changes in relative abundance following fire.

\section{Response competitive ability}

Although neighbors generally inhibited the relative growth of target seedlings (lnRR significantly less than zero), the magnitude of this effect differed substantially among experimental year and target species (significant species $\times$ year effect, Fig. $3 b$ ). Consistent with the hypothesis that competitive rankings drive the pattern of relative abundance following fire, the response to neighbors of Andropogon seedlings became increasingly stronger with time since burning, while the response to neighbors of Ratibida seedlings diminished (Fig. 3b). Hence, in terms of relative growth, Andropogon was least affected by neighbors in 1996, both were competitively equivalent in 1997, and Ratibida was least affected by neighbors in 1998. The pattern of climate variation does not match these patterns, except for a possible effect of drought on the competitive response in 1996, when Andropogon was least affected by competition. 


\section{A) POTENTIAL PERFORMANCE}

\section{Relative growth}

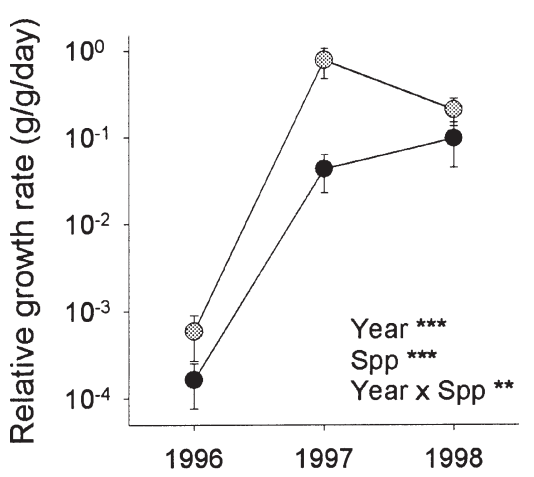

\section{B) EFFECT OF NEIGHBORS}

\section{Relative growth}

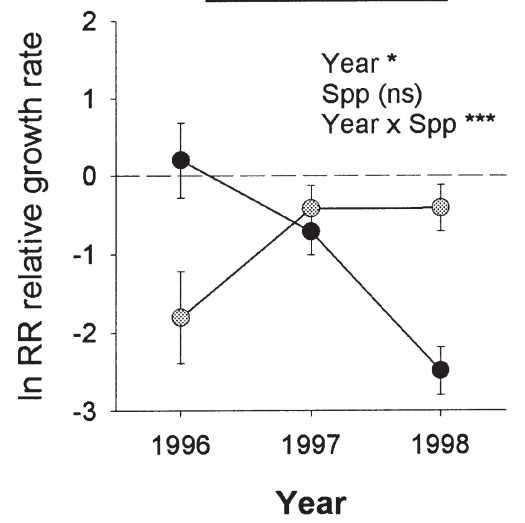

Survival

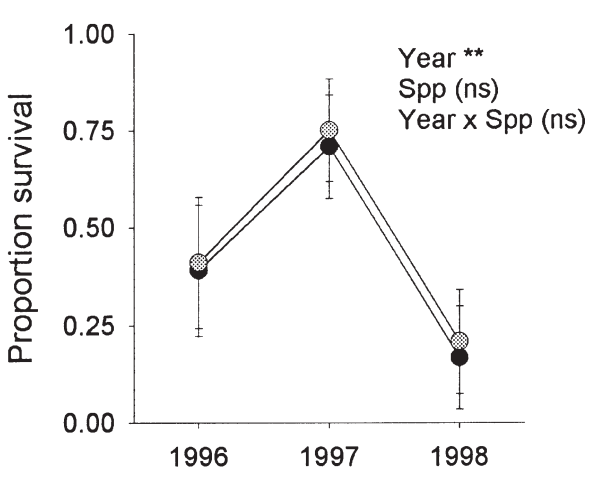

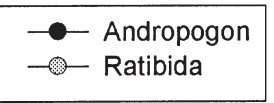

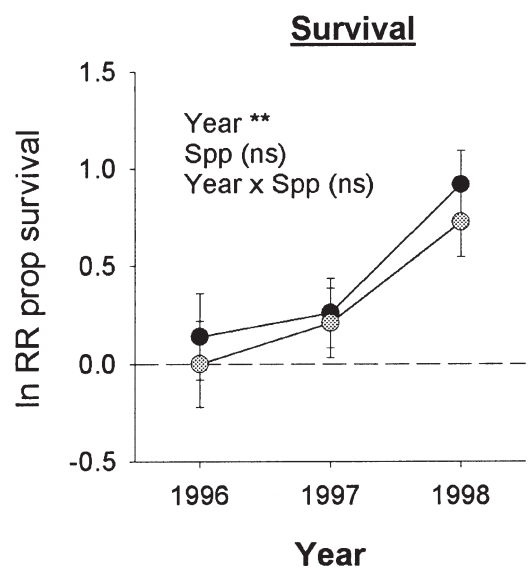

Fig. 3a. Relative growth and survival in the absence of neighbors and $\mathbf{b}$. the effect of neighbors (ln RR) on relative growth and survival of Andropogon (dark circles) and Ratibida (grey circles) seedlings (mean $\pm 1 \mathrm{SE}$ ). Statistical results are from two-way ANOVA models with year and species as fixed factors $(*=P<0.05, * *=P<0.01$, *** $=P<0.005$; ns $=$ non-significant). Ln RR values in b. that are near zero (the dashed line) indicate little effect of neighbors, increasingly negative values indicate competitive effects and increasing positive values indicate facilitative effects. A species is considered a good response competitor if neighbors inhibit it less than they inhibit other species.

Compared to the dramatic change in rankings for RGR, the two targets responded similarly to neighbors in terms of survival (Fig. 3b). Also in contrast to results for growth, neighbors generally facilitated rather than inhibited survival. It appears that the overall facilitative effect of neighbors increased from 1996 to 1998, although the survival response ratio was only significantly facilitative (Ln RR survival different from zero) in 1998, the warmest of the three years. Hence, the effect of neighbors on the survival of the two species was not related to time since burning, inconsistent with the competition hypothesis.

\section{Discussion}

Results support the assumption that competitive interactions in terms of growth change with time since fire and are correlated with post-fire changes in species relative abundance. The $\mathrm{C}_{4}$ grass, Andropogon, was less inhibited by neighbors than the $\mathrm{C}_{3}$ forb species, Ratibida, in the first growing season after a spring burn. As the community recovered from the burn Ratibida seedlings were less inhibited than the Andropogon seedlings by neighbors and the relative abundance of the $\mathrm{C}_{4}$ grasses declined. In contrast, competitive response in terms of survival did not differ among species and interactions became increasingly facilitative over three years following the burn. 
Both alternative predictions were not supported. First, the direct effects of abiotic change following fire (measured by target performance in the absence of neighbors) did not correspond with changes in relative abundances of the two species. Maximal growth rates did not appear to be responsible either for changes in abundance following fire. Another alternative, concerning the effects of other trophic levels of patterns of species abundance, was not tested.

Thus, change in relative abundance of these two species following fire are most closely related to shifts in species growth competitive response ranking, lending support for the common explanation why species relative abundances change due to fire. However, this relationship is potentially influenced by life history stage, climate variation, and species choice. Variation in these other factors, as well as the characteristics of the burns themselves, may explain why other studies have not found such a strong relationship between competitive response rankings and relative abundance following fire.

\section{Fire and competitive rankings}

Abundance patterns were correlated with the effect of neighbors on the growth, but not on the survival, of the two species. Other studies have also found that survival and growth responses are not correlated (e.g. De Steven 1991; Gill \& Marks 1991; Burton \& Bazzaz 1995; Goldberg et al. 1999; Suding \& Goldberg 2001), although it is unclear which parameter more closely controls the population consequences of these interactions. Short-term competitive responses to disturbance may be dominated by the growth rates of individuals while responses of survival to competition may influence community structure over a longer time period. For instance, the presence of neighbors facilitated the survival of Andropogon minimally, but consistently, more than Ratibida. These slight differences in the survival response to neighbors may explain why Andropogon was always more abundant than Ratibida at the study site.

Although these results broadly support the competition hypothesis, this conclusion assumes that fire affects the competitive abilities of seedlings and adults similarly. Increased competitive response rankings of a species at the seedling life history stage could not immediately translate into increased abundance of that species in the adult community unless adult competitive ability was affected similarly. The conditions under which competitive ability is correlated among life history stages are unclear (Grime 1979; Goldberg 1996; Howard \& Goldberg 2001), and it is also unclear how competitive effect ability is related with competitive response ability in adult vegetation (Goldberg \& Landa 1991; Keddy et al. 1994).

\section{Differing effects of fire and climate}

Climate variation appeared to affect seedling performance in the absence of neighbors, while burning more strongly influenced adult vegetation as well as seedling competitive responses to neighboring vegetation. These differences may be attributable to the degree to which climate and neighbors affect resources. Adult plants that are deeply rooted, and seedlings that are buffered by shading by adults, may not respond as strongly to shortterm changes in water availability compared to disturbance-induced changes in soil nutrient and light availability. In contrast, shallow-rooted seedlings without neighbor shade may respond more strongly to changes in climatic variables such as air temperature or water availability.

Although this hypothesis is potentially quite general, it is difficult to evaluate. The few relevant data concern climate and fire effects on total adult productivity and are only partially consistent. Dhillion \& Anderson (1994) compared the effects of burning in two drought years (50\% less precipitation) with two non-drought years and found that burning had a greater impact on productivity than did drought, consistent with the idea that the benefits of release of nutrients and light due to burning outweigh the negative impacts of low water availability. In contrast, Gibson \& Hulbert (1987) found that Andropogon cover was not affected by burning regime but rather only by year-to-year climatic variation, and a model developed by Seastedt et al. (1994) identified photosynthetic pathway and precipitation, but not burning regime, as the most important variables affecting plant production.

\section{Conclusion}

Although changes in plant species competitive ability following fire have often been assumed to be responsible for changes in relative abundances of species following fire, this study presents experimental evidence to support this assumption. However, fire events vary widely and further experiments are needed to determine which types of burn will most likely shift species competitive rankings. Suding \& Goldberg (2001) found that abiotic changes associated with soil mound disturbance (specifically decreased compaction and lower soil moisture), rather than changes in neighborhood characteristics such as biomass and neighbor identity, were responsible for shifts in competitive rankings. Likewise, burns that strongly influence soil characteristics may be more likely to change species competitive rankings than burns that predominately affect vegetation structure. Identifying the relationships among specific types of 
post-disturbance changes and competitive dynamics may help explain why experimental work examining changes in species competitive rankings due to fire has obtained inconsistent results.

Acknowledgements. I thank K. Hartman and P. Suding for help in the field, C. Midkiff for lodging, and the Ohio Department of Natural Resources for permitting me to study the site. I am especially grateful to D. Goldberg for assistance at all stages of this research. Comments from D. Gibson, D. Goldberg, P. Keddy, J.B. Wilson and an anonymous reviewer improved this manuscript. Support came from a Helen Olson Brower Memorial Fellowship, a University of Michigan Rackham Predoctoral Fellowship, and NSF Dissertation Improvement Grant 97-01250.

\section{References}

Abrams, M.D. 1988. Effects of burning regime on buried seed banks and canopy coverage in a Kansas tallgrass prairie (USA). Southwest. Nat. 33: 65-70.

Belsky, A.J. 1992. Effects of grazing, competition, disturbance and fire on species composition and diversity in grassland communities. J. Veg. Sci. 3: 187-200.

Blair, J.M. 1997. Fire, N availability, and plant response in grasslands: a test of the transient maxima hypothesis. Ecology 78: 2359-2368.

Brewer, J.S. 1999. Short-term effects of fire and competition on growth and plasticity of the yellow pitcher plant, Sarracenia alata (Sarraceniaceae). Am. J. Bot. 86: 12641271.

Briggs, J.M. \& Knapp, A.K. 1995. Interannual variability in primary production in tallgrass prairie: climate, soil moisture, topographic position, and fire as determinants of aboveground biomass. Am. J. Bot. 82: 1024-1030.

Burton, P.J. \& Bazzaz, F.A. 1995. Ecophysiological responses of tree seedlings invading different patches of old-field vegetation. J. Ecol. 83: 99-112.

Collins, S.L. 1992. Fire frequency and community heterogeneity in tallgrass prairie vegetation. Ecology 73: 20012006.

Collins, S.L. \& Wallace, L.L. 1990. Fire in North American tallgrass prairie. University of Oklahoma Press, Norman, OK.

De Steven, D. 1991. Experiments on mechanisms of tree establishment in old-field succession: seedling survival and growth. Ecology 72: 1076-1088.

Dhillion, S.S. \& Anderson, R.C. 1994. Production on burned and unburned sand prairies during drought and non-drought years. Vegetatio 115: 51-59.

Ford, M.A. \& Grace, J.B. 1998. The interactive effects of fire and herbivory on a coastal marsh in Louisiana. Wetlands 18: $1-8$.

Gibson, D. J. \& Hulbert, L.C. 1987. Effects of fire, topography and year-to-year climatic variation on species composition in tallgrass prairie. Vegetatio 72: 175-186.
Glenn-Lewin, D.C., Johnson, L.A., Jurik, T.W., Akey, A., Leoschke, M. \& Rosberg, T. 1990. Fire in central North American Grasslands: vegetative reproduction, seed germination and seedling establishment. In: Collins, S.L. \& Wallace. L.L (eds.) Fire in North American tallgrass prairie, pp. 43-56. University of Oklahoma Press, Norman, OK.

Goldberg, D.E. 1996. Competitive ability: definitions, contingency and correlated traits. Philos. Trans. R. Soc. B. 351: 1377-1385.

Goldberg, D.E. \& Landa, K. 1991. Competitive effect and response: hierarchies and correlated traits in the early stages of competition. J. Ecol. 79: 1013-1030.

Goldberg, D.E., Rajaniemi, T., Gurevitch, J. \& Stewart-Oaten, A. 1999. Matching questions and metrics of interaction strength in community ecology. Ecology 80: 1118-1131.

Gurevitch, J. \& Collins, S.L. 1994. Experimental manipulation of natural plant communities. Trends Ecol. Evol. 9: 94-98.

Hedges, L.V., Gurevitch, J. \& Curtis, P.S. 1999. The metaanalysis of response ratios in experimental ecology. Ecology 80: 1150-1156.

Howard, T.G. \& Goldberg, D.E. 2001. Competitive response hierarchies for germination, growth, and survival and their influence on abundance. Ecology 82: 979-990.

Hulbert, L.C. 1988, Causes of fire effects in tallgrass prairie. Ecology 69: 46-58.

Inchausti, P. 1995. Competition between perennial grasses in a neotropical savanna: the effects of fire and of hydricnutritional stress. J. Ecol. 83: 231-243.

Keddy, P.A., Twolan-Strutt, L. \& Wisheu, I.C. 1994. Competitive effect and response rankings in 20 wetland plants: are they consistent across three environments? J. Ecol. 82: 635-643.

Lloret, F. 1998. Fire, canopy cover, and seedling dynamics in Mediterranean shrubland of northeastern Spain. J. Veg. Sci. 9: 417-430.

Marion, G.M., Moreno, J.M. \& Oechel, W.C. 1991. Fire severity, ash deposition, and clipping effects on soil nutrients in chaparral. Soil Sci. Soc. Am. J. 55: 235-240.

Moreno, J.M. \& Oechel, W.C. 1991. Fire intensity effects on germination of shrubs and herbs in southern California chaparral. Ecology 72: 1993-2004.

Morgan, J.W. 1998. Small-scale plant dynamics in temperate Themeda triandra grasslands of southeastern Australia. $J$. Veg. Sci. 9: 347-360.

Noy-Meir, I. 1995. Interactive effects of fire and grazing on structure and diversity of Mediterranean grasslands. $J$. Veg. Sci. 6: 701-710.

Ojima, D.S., Schimel, D.S., Parton, W.J. \& Owensby, C.E. 1994. Long-term and short-term effects of fire on nitrogen cycling in tallgrass prairie. Biogeochemistry 24: 67-84.

Old, S. 1969. Microclimate, fire, and plant production in an Illinois prairie. Ecol. Monogr. 93: 355-384.

Quintana-Ascencio, P.F. \& Menges, E.S. 2000. Competitive abilities of three narrowly endemic plant species in experimental neighborhoods along a fire gradient. Am. J. Bot. 87: 690-699.

Seastedt T.R., Coxwell, C.C., Ojima, D.S. \& Parton, W.J. 
1994. Controls of plant and soil carbon in a semihumid temperate grassland. Ecol. Appl. 4: 344-353.

Suding, K.N. 1999. Processes responsible for changes in species composition following disturbance. Ph.D. Dissertation, University of Michigan, Ann Arbor, MI.

Suding, K.N. \& Goldberg, D.E. 2001. Do disturbances alter competitive hierarchies? Mechanisms of change following gap creation. Ecology 82: 2133-2149.

Turner, C.L. \& Knapp, A.K. 1996. Responses of a $\mathrm{C}_{4}$ grass and three $\mathrm{C}_{3}$ forbs to variation in nitrogen and light in tallgrass prairie. Ecology 77: 1738-1749.

Turner C.L., Blair, J.M., Schwartz, R.J. \& Neel, J.C. 1997. Soil N and plant responses to fire, topography, and supplemental N in tallgrass prairie. Ecology 78: 1832-1843.

Turner, C.L., Kneisler, J.R. \& Knapp, A.K. 1995. Comparative gas exchange and nitrogen responses of the dominant $\mathrm{C}_{4}$ grass Andropogon gerardii and five $\mathrm{C}_{3}$ forbs to fire and topographic position in tallgrass prairie during a wet year. Int. J. Plant Sci. 156: 216-226.

Tyler, C.M. 1996. Relative importance of factors contributing to postfire seedling establishment in maritime chaparral. Ecology 77: 2182-2195.
Vilà, M. \& Terradas, J. 1995. Effects of competition and disturbance on the resprouting performance of the mediterranean shrub Erica multiflora L. (Ericaceae). Am. J. Bot. 82: 1241-1248.

Vilà, M. \& Lloret, F. 2000. Woody species tolerance to expansion of the perennial tussock grass Ampelodesmos mauritanica after fire. J. Veg. Sci. 11: 597-606.

Vilà, M. \& Sardans, J. 1999. Plant competition in Mediterranean-type vegetation. J. Veg. Sci. 10: 281-294.

Voss, W.G. 1972, 1985, 1996. Michigan flora. Cambridge Institute of Science, Ann Arbor, MI.

Whelen, R.J. 1995. The ecology of fire. Cambridge University Press, Cambridge.

Wilson, S.D. \& Shay, J.M. 1990. Competition, fire and nutrients in a mixed-grass prairie. Ecology 71: 1959-1967.

Wilson, S.D. \& Tilman, D. 1995. Competitive responses of eight old-field plant species in four environments. Ecology 76: 1169-1180.
Received 24 October 2000; Revision received 8 June 2001; Accepted 14 September 2001. Coordinating Editor: J.B. Wilson. 